\title{
Author Correction: PQM-1 controls hypoxic survival via regulation of lipid metabolism
}

\author{
Thomas Heimbucher (1), Julian Hog, Piyush Gupta \& Coleen T. Murphy (1)
}

Correction to: Nature Communications https://doi.org/10.1038/s41467-020-18369-w, published online 2 October 2020.

The original version of this Article omitted the following from the Acknowledgements:

Research of T.H. and P.G. in the Baumeister lab was supported by the Deutsche Forschungsgemeinschaft DFG (German Research Foundation under Germany's Excellence Strategy EXC 294 and EXC-2189-Projektnummer 390939984; CRC850-Project ID A06 and CRC1381-Project ID B09 to Ralf Baumeister).

This has now been corrected both the PDF and HTML versions of the Article.

Published online: 20 November 2020

(c) Open Access This article is licensed under a Creative Commons Attribution 4.0 International License, which permits use, sharing, adaptation, distribution and reproduction in any medium or format, as long as you give appropriate credit to the original author(s) and the source, provide a link to the Creative Commons license, and indicate if changes were made. The images or other third party material in this article are included in the article's Creative Commons license, unless indicated otherwise in a credit

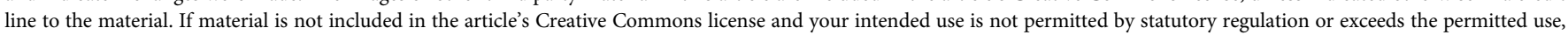
you will need to obtain permission directly from the copyright holder. To view a copy of this license, visit http://creativecommons.org/licenses/by/4.0/.

(C) The Author(s) 2020 